\title{
Tiga dekade riset tentang PCK dalam pendidikan sains (fisika) dan prospek ke depannya
}

\author{
Nadi Suprapto \\ aprodi Pendidikan Fisika, Universitas Negeri Surabaya, Surabaya, 60231, Indonesia \\ ${ }^{b}$ Graduate Institute of Science Education, National Dong Hwa University, Hualien, 97401, Taiwan \\ e-mail: nadisuprapto@unesa.ac.id
}

\begin{abstract}
Abstrak
Penelitian tentang Pedagogical Content Knowledge (PCK) dalam pendidikan sains (Fisika) telah mengalami perkembangan yang signifikan sejak diinisiasi oleh Lee Shulman pada tahun 1986. Tahun demi tahun, para peneliti melakukan modifikasi, melengkapi, bahkan mengkritisi upaya-upaya awal Shulman tersebut, yang semuanya ditujukan untuk memperkuat strand PCK itu sendiri. Sebagai konsekuensinya, terdapat dua model yang mewakili sub strand PCK di dunia: transformative model dan integrative model. Oleh karena itu, paper ini ditujukan untuk mengkaji perkembangan penelitian tentang PCK ini khususnya pada domain fisika. Dengan menggunakan systematic review, penulis meninjau kembali kedua sub strand tersebut. Proses reviu terdiri dari lima tahap: memfokuskan dan mengidentifikasi riset terdahulu yang relevan, mengevaluasi dan mengkritisi, menyajikan contoh-contoh dan bukti-bukti, menafsirkan temuan, dan memberikan rekomendasi. Dengan kata lain, hasil-hasil penelitian PCK dalam domain fisika diuraikan, dicontohkan, dan dianalisis. Hasil penelitian PCK topik gaya dan gerak sebagai representasi model integratif dan hasil penelitian PCK topik semikonduktor sebagai representasi model transformative didiskusikan dalam penelitian ini. Selain itu potensi-potensi riset ke depannya tentang strand ini juga direkomendasikan.
\end{abstract}

Kata Kunci: fisika; PCK; gaya dan gerak; semikonduktor; systematic review

\section{Three decades of research on PCK in science education (physics) and its future prospects}

\begin{abstract}
Research on Pedagogical Content Knowledge (PCK) in science (physics) education has experienced significant development since initiated by Lee Shulman in 1986. Year by year, the researchers modified, complemented and even criticized Shulman's initial efforts, all of which aimed at strengthening the PCK strand itself. As a consequence, there are two models that represent the PCK sub strand in the world: transformative models and integrative models. Therefore, this paper is intended to examine the development of research on PCK, especially in the domain of physics. By using a systematic review, the author reviews these two sub strands. The review process consisted of five stages: focusing and identifying previous research that is relevant, evaluating and criticizing, presenting examples and evidence, interpreting findings, and providing recommendations. In other words, the results of PCK research in the physics domain are described, exemplified, and analyzed. The results of PCK research on the topic of force and motion as a representation of integrative models and the results of PCK research on semiconductor topics as a representation of transformative models were discussed in this study. In addition, future research potentials on this strand are also recommended.
\end{abstract}

Keywords: physics; PCK; force and motion; semiconductor; systematic review

How to Cite: Suprapto, N. (2019). Tiga dekade riset tentang PCK dalam pendidikan sains (fisika) dan prospek ke depannya. Jurnal Pendidikan Fisika dan Keilmuan (JPFK), 5(1), 15-24. doi:http://dx.doi.org/10.25273/jpfk.v5i1.3338 


\section{PENDAHULUAN}

Lee Shulman mendeskripsikan pedagogical content knowledge (PCK) sebagai "special amalgam of content and pedagogy that is uniquely the province of teachers, their own special form of professional understanding" (L. Shulman, 1987). Shulman menekankan pentingnya PCK sebagai karakteristik khusus yang membedakan seorang guru dengan pengetahuan akan isi materi atau konten tertentu dengan guru lain dalam menyatakan ide-idenya sebagai bentuk profesionalismenya. Dengan kata lain, PCK adalah kombinasi pengetahuan guru terhadap materi pembelajaran, keterampilan pedagogik, konteks, dan situasi belajar, termasuk pengetahuan akan peserta didiknya. Dalam pembelajaran fisika, pengetahuan yang dimaksud berarti semua pengetahuan guru fisika akan materi fisika, keterampilan-keterampilan pedagogik, dan pengetahuan akan peserta didik. Kennedy, Ball, dan McDiarmid menyederhanakan pengetahuan guru menjadi 'a teaching act', yaitu pengetahuan tentang materi pembelajaran, pengetahuan akan peserta didik, pengetahuan tentang pembelajaran, pengetahuan terkait keterampilan pedagogik, pengetahuan tentang peran guru, dan pengetahuan seputar kurikulum (Kennedy, Ball, \& McDiarmid, 1993).

Sementara itu, pada awalnya Shulman mengkategorikan basis pengetahuan menjadi tujuh kategori: (1) pengetahuan akan isi pelajaran/ konten (Content Knowledge-CK) atau pengetahuan akan subyek/materi (Subject Matter KnowledgeSMK), (2) pengetahuan pedagogik umum (Pedagogical Knowledge-PK), (3) pengetahuan akan kurikulum (Curricular Knowledge-CurrK), (4) pengetahuan konten pedagogik (PCK), (5) pengetahuan peserta didik dan karakteristiknya, (6) pengetahuan tentang konteks pendidikan, dan (7) pengetahuan tentang tujuan pendidikan, nilai-nilai, landasan filosofis dan historis (L. Shulman, 1987; L. S. Shulman, 1986). Dari tahun ke tahun, banyak peneliti pendidikan sains termasuk pendidikan fisika di dalamnya, melakukan perubahan dengan memodifikasi kategori tersebut. Sebagai contoh, Grossman dan Magnusson mengajukan empat domain pengetahuan: SMK dan beliefs, PK dan beliefs, PCK dan beliefs, dan pengetahuan--contextual beliefs (Grossman, 1990; Magnusson, Krajcik, \& Borko, 1999). Baru-baru ini, sekelompok peneliti, Kirschner dkk menyederhanakan pengetahuan yang hanya pada tiga kategori saja namun lebih operasional: CK, PCK, dan PK (Kirschner, Borowski, Fischer, Gess-Newsome, \& von Aufschnaiter, 2016).

Selama perkembangannya dari tahun 1986 sampai saat ini (atau lebih tepatnya selama kurun waktu tiga dekade), terdapat dua 'pengutuban' model PCK: "model transformatif" dan "model integratif". Model transformatif menyatakan bahwa CK atau SMK dapat dianalisis terpisah dengan PCK, sebagai komponen yang berkontribusi terhadap pembentukan PCK, namun bukan sebagai satu kesatuan yang utuh (Grossman, 1990; Kind, 2009, 2015; Padilla \& Garritz, 2015; L. Shulman, 1987). Di sisi lain, model integratif tidak mengenali PCK sebagai komponen pengetahuan yang terpisah, PCK digunakan untuk menggambarkan pengetahuan guru secara keseluruhan, yang terdiri dari pengetahuan akan isi materi pelajaran (CK), pengetahuan pedagogik (PK) dan konteks pembelajaran. Dalam model integratif, SMK (atau CK) adalah bagian dari PCK (Daehler, Heller, \& Wong, 2015; Gess-Newsome, 2015; Kirschner et al., 2016).

Sebagai penganut model integratif, penulis memposisikan dirinya bahwa CK dan PCK sebagai satu kesatuan yang utuh yang ditunjang oleh keterampilan pedagogik umum (PK). Sebuah model teoretis sederhana PCK yang 'beraliran' integratif yang diadopsi dari model Kirschner adalah sebagai berikut (lihat Gambar 
1) (Kirschner et al., 2016; Kirschner, Taylor, Rollnick, Borowski, \& Mavhunga, 2015; Suprapto, 2017).

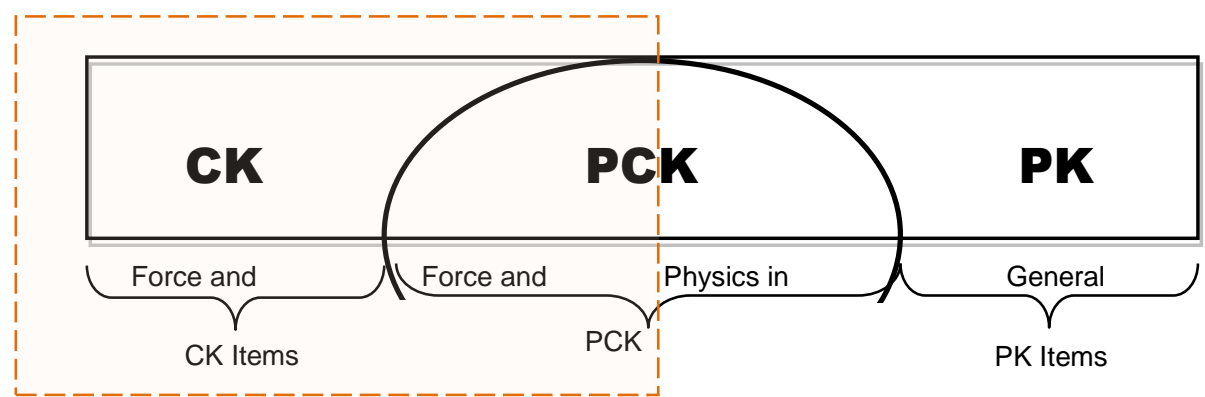

Gambar 1. Penyederhanaan model PCK dari Kirschner et al. (2016)

Gambar 1 memberikan implikasi bahwa seorang guru fisika harus menguasai pengetahuan (CK, PCK, dan PK) secara keseluruhan. Sebagai contoh untuk pengetahuan akan konten tentang gaya dan gerak yang dipadu dengan pengetahuan fisika secara umum akan berkontribusi terhadap pengetahuan PCK. Pengetahuan akan konsep fisika yang umum ini tentunya harus diikuti oleh pengetahuan pedagogik yang membantu dalam pelaksanaan atau proses pembelajaran. Dari situ juga jelas bahwa untuk butir-butir pengetahuan PCK harus berisi integrasi antara butir-butir konten fisika spesifik (misal gaya dan gerak) dan butir-butir pengetahuan pedagogik. Berawal dari rasional ini maka pada pemaparan bagian selanjutnya terdiri dari kajian singkat perkembangan penelitian tentang PCK ini khususnya pada domain fisika, uraian hasil-hasil penelitian PCK dalam domain fisika yang tentunya merepresentasikan keberadaan kedua strand, dan beberapa rekomendasi untuk kemungkinan pengembangan penelitian ke depannya.

\section{METODE PENELITIAN}

Penulisan artikel ini ditujukan untuk mengkaji perkembangan penelitian tentang PCK khususnya pada bidang pembelajaran fisika. Dengan menggunakan systematic review (reviu sistematik), proses reviu terdiri dari lima tahap: memfokuskan dan mengidentifikasi riset terdahulu yang relevan, mengevaluasi dan mengkritisi, menyajikan contoh-contoh dan bukti-bukti, menafsirkan temuan, dan memberikan rekomendasi (Suprapto, 2016; Suprapto \& Chang, 2015). Dengan kata lain, hasil-hasil penelitian PCK dalam domain fisika diuraikan, dicontohkan, dan dianalisis. Dua contoh hasil penelitian tentang gaya-gerak dan semikonduktor disajikan pada bagian hasil dan pembahasan. Selain itu potensi-potensi riset selanjutnya tentang strand PCK juga direkomendasikan.

\section{HASIL DAN PEMBAHASAN}

\section{Tiga Dekade Penelitian PCK Terhadap Calon Guru dan Guru Sains (Fisika)}

Selama kurun waktu kurang lebih 30 tahun, banyak peneliti menyelidiki PCK bagi calon guru maupun guru sains khususnya fisika (Daehler et al., 2015; GessNewsome, 2015; Kind, 2009, 2015; Kirschner et al., 2016; Kirschner et al., 2015; Magnusson et al., 1999; Padilla \& Garritz, 2015; Suprapto, 2017). PCK bagi calon guru fisika menjadi penting karena pemahaman menyeluruh dan koheren tentang isi materi pelajaran dan bagaimana menyampaikannya sangat diperlukan sebagai prasyarat untuk pengembangan pengajaran fisika yang efektif. Sementara itu bagi 
guru fisika, PCK akan berkontribusi kepada pengembangan profesionalismenya. Kualitas PCK bergantung pada koherensi antar komponen serta kekuatan komponen-komponen secara individual.

Kurang lebih dua puluh tahun setelah pertama kali dikenalkan, akhirnya sebuah model baru, 'Pentagon model' diusulkan dalam mengeksplorasi komponenkomponen PCK (Park \& Oliver, 2008). Model Pentagon mengeksplorasi dan mengintegrasikan lima komponen PCK, yang meliputi: (a) orientasi terhadap pengajaran sains, (b) pengetahuan tentang karakteristik peserta didik, (c) pengetahuan tentang Strategi pembelajaran dan representasi instruksional, (d) pengetahuan tentang kurikulum, dan (e) pengetahuan tentang penilaian pembelajaran. Berdasarkan komponen PCK tersebut, terdapat perbedaan dalam konteks, bagaimana fisikawan di laboratorium dan guru fisika akan merencanakan dan mengajarkan pelajaran fisika. Fisikawan mungkin bisa memberi tahu peserta didik tentang topik tertentu, namun guru fisika yang terampil merencanakan pembelajarannya berdasarkan karakteristik peserta didiknya, apa yang perlu mereka pelajari, dan bagaimana cara terbaik untuk mempelajarinya. Saat mengajar, dia terus mengevaluasi pembelajaran dan menggunakan berbagai strategi pedagogik yang memungkinkannya untuk mengubah penjelasan, menciptakan demonstrasi, membimbing eksperimen, dan memberikan analogi yang akan mendukung pemahaman siswa. Keterampilan komunikasi efektif atau mampu menyampaikan pengetahuan secara efektif kepada peserta didik merupakan dasar dari PCK (Morrison \& Luttenegger, 2015).

Pada tahun 2012, dari kontribusinya pada PCK Summit di Colorado, USA, Shulman mengungkapkan setidaknya empat keterbatasan utama dari rumusan awal PCK: (1) PCK tanpa atribut non-kognitif: emosi, pengaruh, perasaan, dan motivasi; (2) PCK kurang memadai dalam tindakan pedagogik, (3) PCK kurang memperhatikan konteks sosial dan budaya yang lebih luas, dan (4) PCK benarbenar tidak cukup memberikan hasil belajar (learning outcomes) dalam karya awalnya (L. S. Shulman, 2015). Berawal dari sini akhirnya disepakati model baru sebagai hasil konsensus terkait pengetahuan professional guru, topic spesific professional knowledge (TSPK) dari Gess-Newsome dan tim yang juga berpartisipasi dalam PCK Summit tersebut yang tetap mewadahi dua kelompok besar atau strand-strand PCK: transformative model dan integrative model (GessNewsome, 2015).

Untuk mengukur dan mengeksplorasi PCK sudah berkontribusi dalam upaya peningkatan profesionalisme guru fisika, tentunya diperlukan metodologi tertentu dan melibatkan instrumen yang tertentu pula. Beberapa peneliti sebelumnya berpendapat bahwa PCK sulit diukur secara langsung karena kurangnya model dan alat uji (Olszewski, 2010). Oleh karena itu, pengamatan saja terhadap kelas fisika tidak akan mengungkap lebih jauh level profesionalnya. Sehingga, beberapa teknik atau metode dalam meneliti PCK digunakan. Penulis merangkum beberapa metodologi yang ditujukan dalam rangka bagaimana meng-capture PCK: evaluasi multi-metode, wawancara terstruktur, wawancara semi-terstruktur, pengamatan/observasi, pemetaan konsep, wawancara kepada guru, wawancara kepada siswa-guru, analisis materi pembelajaran, butir-butir tes, konstruksi skala PCK via survei dengan kuisioner, rubriks PCK, analisis atas rekaman video, content-representations (CoRes) dan professional-experience repertoires (PaPeRs).

Pada dasarnya PCK tidak dapat diukur melalui satu pendekatan/ metode saja. Di antara metode-metode di atas, hanya sedikit penelitian tentang 
pengonstruksian factor-faktor PCK dalam skala butir (item scale) yang digunakan (Kirschner et al., 2015; Park, Suh, \& Seo, 2018). Oleh karena itu, pada bagian berikutnya akan disajikan masing-masing sebuah contoh hasil riset dimana aspekaspek PCK diukur melalui skala kuesioner dan dilanjutkan dengan wawancara semi-struktur.

\section{Hasil-Hasil Penelitian PCK dalam Domain Fisika Penelitian PCK tentang gaya dan gerak}

Berikut ini penulis sajikan hasil penelitian yang mengadopsi model integratif tentang gaya dan gerak dimana PCK dieksplorasi melalui skala kuisioner (Suprapto, 2017). Penelitian yang dilakukan terhadap calon guru fisika di Jawa Timur ini mengeksplorasi delapan dimensi/ faktor PCK sebagai fokus penelitian. Kuesioner PCK terdiri dari delapan dimensi: pengetahuan tentang praktik-praktik sains (KSP), pengetahuan tentang kebiasaan berpikir-habbits of minds (KHM), pengetahuan tentang strategi-strategi pembelajaran (KIS), pengetahuan tentang peserta didik (termasuk kesulitan yang dialami) (KS), pengetahuan tentang representasi-konten (KCR), pengetahuan tentang pemahaman siswa (KSU), pengetahuan tentang asesmen (KA), dan pengetahuan terkait kurikulum (CurrK). Di antara dimensi-dimensi ini (lihat Tabel 1), dimensi pengetahuan akan peserta didik (KS) berada di level pertama $(M=4,16, S D=0,50)$ diikuti oleh pengetahuan tentang strategi pembelajaran (KIS) $(M=3,99, S D=0,53)$, pengetahuan tentang kebiasaan berpikir (KHM) $(M=3,88, S D=0,53)$, dan pengetahuan tentang representasi representasi-konten $(\mathrm{KCR})(\mathrm{M}=3,79, \mathrm{SD}=0,51)$. Keempat dimensi ini mendapatkan rata-rata (mean) lebih besar dari rata-rata total (grand mean) $(3,77)$. Sebaliknya, pengetahuan tentang kurikulum (CurrK) berada di posisi paling bawah $(\mathrm{M}=3,42, \mathrm{SD}=0,46)$.

Table 1. Rangkuman tentang tingkatan diantara dimensi-dimensi PCK dari calon guru fisika (Suprapto, 2017)

\begin{tabular}{llllll}
\hline Dimensi PCK & $\begin{array}{c}\text { Mean } \\
(\mathbf{M})\end{array}$ & $\begin{array}{c}\text { Standard } \\
\text { Deviation (SD) }\end{array}$ & Skewness & Kurtosis & Ranking \\
\hline KS & 4,16 &, 50 &,- 093 &,- 093 & $1^{*}$ \\
KIS & 3,99 &, 53 &,- 167 &,- 042 & $2^{*}$ \\
KHM & 3,88 &, 53 &, 011 &, 028 & $3^{*}$ \\
KCR & 3,79 &, 51 &,- 173 &, 809 & $4^{*}$ \\
KA & 3,70 &, 53 &, 048 &, 148 & 5 \\
KSP & 3,64 &, 51 &,- 189 &, 347 & 6 \\
KSU & 3,58 &, 54 &, 083 &, 004 & 7 \\
CurrK & 3,42 &, 46 &,- 307 & 1,004 & 8 \\
PCK (Total) & $\mathbf{3 , 7 7}$ &, 36 &,- 037 &, 277 & \\
\hline
\end{tabular}

Catatan: *, mean > grand mean, KS=knowledge of student, KIS=knowledge of instructional strategies, $K H M=k n o w l e d g e$ of habit of minds, KCR=knowledge of content- representations, $K A=k n o w l e d g e$ of assessment, $K S P=k n o w l e d g e$ of science-practice, KSU=knowledge of student understanding, CurrK=curricular knowledge 
Tabel 2 mengilustrasikan hubungan diantara dimensi-dimensi PCK. Secara umum, semua koefisien korelasi secara signifikan positif $(p<.01)$, berkisar antara 0, 277 sampai 0,582. Ini berarti konstruksi butir/ item dari setiap dimensi saling berkorelasi. Bila koefisien korelasi dalam rentang 0,35-0,65, berarti berguna dalam memberikan prediksi yang terbatas. Nilai-nilai tersebut memberikan ciri khas yang digunakan untuk mengidentifikasi keanggotaan variabel dalam prosedur statistik analisis faktor (factor analysis: EFA dan CFA).

Table 2. Korelasi antara dimensi-dimensi PCK (Suprapto, 2017)

\begin{tabular}{lcccccccr}
\hline Dimensi PCK & 1 & 2 & 3 & 4 & 5 & 6 & 7 & 8 \\
\hline 1 KSP & 1 & & & & & & & \\
2 KHM & $0,384^{* *}$ & 1 & & & & & & \\
3 KIS & $0,394^{* *}$ & $0,582^{* *}$ & 1 & & & & & \\
4 KS & $0,285^{* *}$ & $0,432^{* *}$ & $0,568^{* *}$ & 1 & & & & \\
$5 \mathrm{KCR}$ & $0,355^{* *}$ & $0,477^{* *}$ & $0,469^{* *}$ & $0,360^{* *}$ & 1 & & & \\
$6 \mathrm{KSU}$ & $0,277^{* *}$ & $0,339^{* *}$ & $0,428^{* *}$ & $0,433^{* *}$ & $0,426^{* *}$ & 1 & & \\
$7 \mathrm{KA}$ & $0,311^{* *}$ & $0,386^{* *}$ & $0,520^{* *}$ & $0,510^{* *}$ & $0,379^{* *}$ & $0,534^{* *}$ & 1 & \\
$8 \mathrm{CurrK}$ & $0,320^{* *}$ & $0,303^{* *}$ & $0,419^{* *}$ & $0,381^{* *}$ & $0,366^{* *}$ & $0,462^{* *}$ & $0,449^{* *}$ & 1 \\
\hline${ }^{* *} p<0,01$ & & & & & & & &
\end{tabular}

\section{Penelitian PCK tentang semikonduktor}

Untuk sajian kedua ini sebagai representasi penelitian yang berpedoman pada model transformatif. Penulis memfokuskan perhatiannya pada, bagaimana penggunaan CoRes membantu mengeksplorasi PCK guru fisika (Rollnick, 2017). Penelitian difokuskan pada, bagaimana perkembangan CK guru saat terlibat dalam sebuah proyek mengembangkan pengajaran semikonduktor?; dan bukti-bukti tentang pengetahuan profesional spesifik dan PCK dalam praktik yang muncul dalam proses ini?.

Adapun sumber data utama untuk melacak perkembangan CK guru adalah peta konsep, meskipun sumber data lain seperti jurnal guru, hasil wawancara dan laporan proyek juga digunakan. Untuk pertanyaan selanjutnya, sumber data yang digunakan adalah wawancara, jurnal guru, rekaman audio pengajaran sebaya dan laporan proyek yang dirancang untuk 16 minggu. CoRes yang dirancang dalam proses pengumpulan data (Minggu 3) (lihat rincian di bawah) berperan sebagai penggambaran TSPK untuk keseluruhan guru dan digunakan sebagai referensi di sepanjang TSPK awal mereka. Misalnya, CoRe adalah titik awal pengembangan pembelajaran para guru (Rollnick, 2017).

"Minggu 1: Semua guru dilengkapi dengan lembar kerja proyek yang menjelaskan tujuan proyek dan uraian singkat metodologi yang diajukan serta pembacaan pedoman yang berkaitan dengan aspek-aspek utama proyek.

Minggu 2: Kedua supervisor memberikan presentasi interaktif kepada para guru mengenai topik semikonduktor, dari sudut pandang fisika dan kimia. Guru diingatkan bagaimana membangun peta konsep. Para guru menggambar peta konsep pertama mereka setelah sesi ini.

Minggu 3: Guru dan supervisor membangun CoRe yang berfungsi sebagai representasi awal PCK untuk keseluruhan kelompok

Minggu 4: Guru menyiapkan dua rencana pembelajaran tentang semikonduktor. Pembelajaran kedua dirancang untuk menjadi wahana diskusi tentang tugas yang telah dikaji oleh guru. 
Minggu 5-6: Bagian penting dari salah satu desain pembelajaran yaitu peer lesson dan pemberian kritik antar guru. Pelaksanaan peer lesson direkam, selanjutnya para guru menggambar peta konsep kedua sebagai latihan di rumah.

Minggu 7: Pembelajaran direvisi setelah peer lesson. Semua guru (4 orang) dan kepala sekolah yang berpartisipasi dalam proyek mengikuti pembelajaran semikonduktor hasil rekaman saat peer lesson sebelumnya.

Minggu 8-9: Para guru menggambar peta konsep ketiga sebelum mengajar. Setiap guru mengajar dan merekam video dua pembelajaran tentang topik tersebut kepada peserta didik mereka.

Minggu 10-15: (Periode menulis). Guru mengirimkan draft tulisan mereka untuk mendapatkan komentar dan umpan balik. Supervisor juga mewawancarai guru yang terlibat proyek tentang bagaimana perasaan mereka selama ambil bagian dalam proyek ini.

Minggu 16: Para guru menyampaikan laporan tertulis tentang proyek mereka untuk diberikan penilaian. Materi laporan meliputi rencana pembelajaran, lembar kerja, dan contoh jawaban siswa, dan catatan jurnal selama proses pembelajaran berlangsung."

Selanjutnya hasil dari progres guru terkait dengan pembuatan peta konsep dapat dianalisis. Contoh-contoh hasil pembuatan peta konsep semikonduktor, mulai dari peta konsep pertama, kedua, dan ketiga dapat dicermati secara detil di daftar rujukan nomor (Rollnick, 2017).

\section{Potensi Pengembangan Penelitian Tentang PCK ke Depannya}

Berdasarkan penelitian-penelitian terdahulu dan beberapa proyek penelitian yang dilakukan oleh penulis, berikut ini dirangkum beberapa implikasi dan potensi pengembangan penelitian PCK ke depannya. Implikasi yang dimaksud meliputi teoritis-empiris, pedagogis, dan praktis bagi calon guru maupun guru fisika. Dari sisi teoritis, pertama, beberapa penelitian tentang PCK memberikan kerangka teoretis baru dalam komunitas pendidikan sains-fisika tentang pengetahuan baik CK maupun PCK itu sendiri sebagai variabel prediktor bagi- (seperti self-efficacy untuk pengajaran fisika) atau variabel prediktif untuk- (seperti sebagai konsepsi pembelajaran fisika) (Suprapto, Chang, \& Ku, 2017). Kedua, di luar implikasi empiris dan teoritisnya, penelitian PCK memperkaya khasanah metodologi dalam mendesain CK dan PCK bersama-sama lebih eksplisit, terlihat, dan mudah diakses. Ketiga, penelitian-penelitian tentang PCK memperkaya kajian literatur dalam pendidikan sains-fisika, terutama Indonesia yang mungkin saja memiliki perspektif yang berbeda dengan negara-negara barat. Sebagai contoh, penelitian tentang gaya dan gerak juga menunjukkan bahwa self-efficacy untuk pengajaran fisika dapat dijelaskan oleh CK dan PCK secara bersama-sama dengan persentase rendah (sekitar 17\% dari variansnya) (Suprapto, 2017). Hasil ini bisa jadi sedikit berbeda saat diimplementasikan di negara lain.

Adapun secara pedagogis, peningkatan aspek-aspek pengajaran pedagogik akan memperkaya informasi tentang aspek-aspek PCK. Sebagai konsekuensinya, di level pendidikan calon guru fisika, eksplorasi pengetahuan tentang kesulitan yang dialami peserta didik, strategi pembelajaran, kebiasaan berpikir, representasi konten/ isi pembelajaran, penilaian, praktik sains, pemahaman siswa, dan pengetahuan akan kurikulum harus diintegrasikan dalam kurikulum pendidikan calon guru fisika ini. Selain itu, memposisikan peran guru atau calon guru fisika, yang tidak hanya mengajar, tapi juga mendidik harus diintegrasikan ke dalam keterampilan-keterampilan pedagogik. Studi tentang PCK membuka kesempatan 
untuk melakukan investigasi terhadap pemahaman mendalam tentang bagaimana satu komponen berhubungan dengan komponen lain, atau bahkan ke keseluruhan PCK, dan selanjutnya bisa diuji efektifitasnya. Perlu dicatat bahwa peningkatan pengetahuan dalam satu komponen mungkin tidak cukup untuk men-trigger perubahan dalam praktik di lapangan.

Terkait dengan implikasi praktis, pertama, walaupun kebijakan pendidikan Indonesia top down, namun pemerintah seharusnya memberikan keleluasaan kepada mereka, (dengan meminjam istilah dari dari Sickel dkk) (Sickel, Banilower, Carlson, \& Van Driel, 2015), "policies should not appropriate PCK, but rather afford structures and supports to facilitate teachers' ongoing PCK development", oleh karena itu dengan memberi lebih banyak kesempatan kepada mereka seharusnya dilakukan pengambil kebijakan. Kedua, pengajar di universitas juga harus memperhatikan beberapa masalah, seperti di konsep gaya dan gerak: impetus idea, force implies motion, dominance idea in Newtonian mechanics, dan actionreaction pairs (Suprapto, 2017).

Ada beberapa keterbatasan dalam penelitian PCK terdahulu sehingga ada peluang untuk pengembangan ke depannya. Sebagai contoh kita ambil dari hasil penelitian yang pertama (Suprapto, 2017). Pertama, penelitian hanya mencakup tiga universitas negeri yang memiliki program persiapan guru fisika sekolah menengah di Indonesia. Penelitian lebih lanjut dapat dilakukan dengan ukuran sampel yang lebih besar dan area yang representatif. Penelitian dengan menyertakan responden/ sampel dalam cakupan yang lebih luas (yaitu di seluruh pulau di Indonesia) sangat direkomendasikan. Melibatkan LPTK swasta/ privat juga disarankan. Kedua, penelitian hanya difokuskan pada level ketiga (junior) dan keempat (senior) di prodi pendidikan fisika, penelitian selanjutnya perlu memperhatikan program Pendidikan Profesi Guru (PPG). Selanjutnya, studi tentang guru fisika (in-service physics teacher) juga berpeluang untuk dilakukan. Sehingga ke depannya dapat dipetakan 'learning progression' diantara calon guru fisika di S1 dan peserta PPG (selanjutnya sebagai pre-service teacher), guru pemula (novice teacher), dan guru senior (in-service teacher).

Ketiga, penelitian 'longitudinal study' seharusnya juga bisa dilakukan untuk memantau profesionalisme guru yang dimulai dari saat mereka sebagai calon guru. Penelitian selanjutnya tentang 'learning progression of PCK' akan membantu menginformasikan tingkat pengetahuan dan keterampilan. Pertanyaan yang mungkin untuk penelitian selanjutnya yaitu bagaimana perkembangan pengetahuan konten dan pengetahuan konten pedagogik mereka, dari tahun ke tahun?. Keempat, penelitian yang dilakukan (Suprapto, 2017), menggunakan survei dan dilanjutkan dengan wawancara semi terstruktur, dalam penelitian selanjutnya, pengamatan di kelas selama lokakarya pengajaran, praktik pelatihan guru melalui program pengalaman lapangan, atau proses belajar mengajar di kelas juga dapat diterapkan untuk lebih mengeksplorasi konsepsi mereka tentang fisika (Suprapto et al., 2017), pengetahuan tentang pembelajaran dan pengajaran fisika.

Kelima, mengintegrasikan teknologi dalam pembelajaran fisika harus dipertimbangkan dalam penelitian masa depan. Sebagai contoh, pengintegrasian teknologi pembelajaran dalam PCK (TPACK) seharusnya sebagai tema baru penelitian pendidikan fisika di Indonesia. Akhirnya, keenam, untuk mengeksplorasi lebih lanjut butir-butir yang mengonstruksi dimensi dari PCK, dapat melibatkan analisis statistik terkini mulai dari Exploratory Factor Analysis (EFA), Confirmatory Factor Analysis (CFA), dan Rasch Analysis. Kita ambil salah satu contoh, CFA, dengan pemodelan persamaan struktural disarankan dalam penelitian lanjutan. 


\section{KESIMPULAN}

Penelitian tentang Pedagogical Content Knowledge (PCK) khususnya dalam pendidikan Fisika telah mengalami perkembangan yang signifikan selama kurun waktu tiga dekade. Untuk itu telah dipaparkan reviu singkat terhadap perkembangan penelitian tentang PCK terhadap calon guru dan guru sains (fisika). Pembahasan juga dilengkapi dengan uraian beberapa hasil penelitian PCK dalam domain Fisika, khususnya tentang gaya dan gerak dan semikonduktor, dimana penulis terlibat dalam kedua proyek tersebut. Beberapa implikasi penelitian tentang PCK, yang meliputi sisi teoritis-empiris, pedagogis, dan praktis bagi calon guru maupun guru fisika juga telah dinarasikan. Begitu pula, beberapa rekomendasi terkait potensi pengembangan penelitian tentang PCK ke depannya juga diajukan.

\section{Ucapan Terima Kasih}

Ucapan terima kasih disampaikan khususnya kepada Prof. Chih-Hsiung Ku dan Prof. Te Sheng Chang sebagai promotor saat penulis menempuh S3 di National Dong Hwa University, Hualien, Taiwan. Selain itu ucapan terima kasih juga disampaikan kepada Prof. Marissa Rollnick dari University Witwatersrand, Johannesburg, South Africa yang memberi kesempatan untuk berdiskusi khususnya tentang PCK pada SK Abell Institute 2017 di National Taiwan Normal University, Taiwan.

\section{REFERENCES}

Daehler, K. R., Heller, J. I., \& Wong, N. (2015). Supporting growth of pedagogical content knowledge in science. In Re-examining pedagogical content knowledge in science education (pp. 55-69): Routledge.

Gess-Newsome, J. (2015). A model of teacher professional knowledge and skill including PCK: Results of the thinking from the PCK Summit. In Re-examining pedagogical content knowledge in science education (pp. 38-52): Routledge.

Grossman, P. L. (1990). The making of a teacher: Teacher knowledge and teacher education: Teachers College Press, Teachers College, Columbia University.

Kennedy, M. M., Ball, D. L., \& McDiarmid, G. W. (1993). A study package for examining and tracking changes in teachers' knowledge (Vol. 93): National Center for Research on Teacher Education, Michigan State University.

Kind, V. (2009). Pedagogical content knowledge in science education: perspectives and potential for progress. Studies in science education, 45(2), 169-204.

Kind, V. (2015). On the beauty of knowing then not knowing. Re-examining pedagogical content knowledge in science education, 178-195.

Kirschner, S., Borowski, A., Fischer, H. E., Gess-Newsome, J., \& von Aufschnaiter, C. (2016). Developing and evaluating a paper-and-pencil test to assess components of physics teachers' pedagogical content knowledge. International Journal of Science Education, 38(8), 1343-1372.

Kirschner, S., Taylor, J., Rollnick, M., Borowski, A., \& Mavhunga, E. (2015). Gathering evidence for the validity of PCK measures. Re-examining pedagogical content knowledge in science education, 229-241.

Magnusson, S., Krajcik, J., \& Borko, H. (1999). Nature, sources, and development of pedagogical content knowledge for science teaching. In Examining pedagogical content knowledge (pp. 95-132): Springer.

Morrison, A. D., \& Luttenegger, K. C. (2015). Measuring pedagogical content knowledge using multiple points of data. The Qualitative Report, 20(6), 804816. 
Olszewski, J. (2010). The Impact of Physics Teachers' Pedagogical Content Knowledge on Teacher Actions and Student Outcomes (Vol. 109): Logos Verlag Berlin $\mathrm{GmbH}$.

Padilla, K., \& Garritz, A. (2015). Tracing a research trajectory on PCK and chemistry university professors' beliefs. In Re-examining pedagogical content knowledge in science education (pp. 85-97): Routledge.

Park, S., \& Oliver, J. S. (2008). Revisiting the conceptualisation of pedagogical content knowledge (PCK): PCK as a conceptual tool to understand teachers as professionals. Research in science Education, 38(3), 261-284.

Park, S., Suh, J., \& Seo, K. (2018). Development and validation of measures of secondary science teachers' PCK for teaching photosynthesis. Research in science Education, 48(3), 549-573.

Rollnick, M. (2017). Learning about semi conductors for teaching-The role played by content knowledge in pedagogical content knowledge (PCK) development. Research in science Education, 47(4), 833-868.

Shulman, L. (1987). Knowledge and teaching: Foundations of the new reform. Harvard educational review, 57(1), 1-23.

Shulman, L. S. (1986). Those who understand: Knowledge growth in teaching. Educational researcher, 15(2), 4-14.

Shulman, L. S. (2015). PCK: Its genesis and exodus. In Re-examining pedagogical content knowledge in science education (pp. 13-23): Routledge.

Sickel, A. J., Banilower, E., Carlson, J., \& Van Driel, J. (2015). Examining PCK research in the context of current policy initiatives. Re-examining pedagogical content knowledge in science education, 199-213.

Suprapto, N. (2016). What should educational reform in Indonesia look like?-Learning from the PISA science scores of East-Asian countries and Singapore. Paper presented at the Asia-Pacific Forum On Science Learning \& Teaching.

Suprapto, N. (2017). The effect of conceptions of physics learning, content knowledge (CK), pedagogical content knowledge (PCK) on self-efficacy for physics teaching among pre-service teachers (PSTs) in Indonesia. (Dissertation). National Dong Hwa University, Taiwan.

Suprapto, N., Chang, T.-S., \& Ku, C.-H. (2017). Conception of learning physics and self-efficacy among Indonesian university students. Journal of Baltic Science Education, 16(1), 7-19.

Suprapto, N., \& Chang, T. (2015). Research on university student's self-efficacy scale in science education: A systematic review. Paper presented at the Proceeding of International Conference on Science and Science Education (IConSSE 2015). 